الإنشاء الطلبي في ديوان النابغة الذبياني

\author{
إعــداد \\ أ. محمد فواز عرسان غنام \\ محاضر متفرغ بكلية الزرقاء الجامعية \\ جامعة البلقاء التطبيقية
}

مجلة الدراسات التريوية والانسانية ـ كلية التربية ـ جامعة دمنهور .

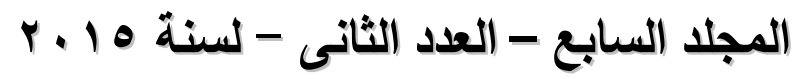


مجلة الدراسات التريوية والانسانية ـ كلية التربية ـ جامعة دمنهور ـ المجلد السابع - العدد (ץ)- لسنة ه 1 ـ ب

\section{الإنشاء الطلبي في ديوان النابغة الذبياني}

أ. محمد فواز عرسان غنام

ملخص

بحثت الدراسـة الإنشاء الطلبي: الأمر ، والاستقهام، والنهي، والنداء، والتمني

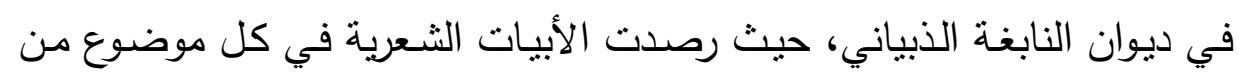

موضوعات الإنشاء الطلبي والمعاني البلاغية التي خرج إليها.

والجديد في هذه الدراسة أنها الأولى التي درست الجملة الطلبية في شعر شاعر

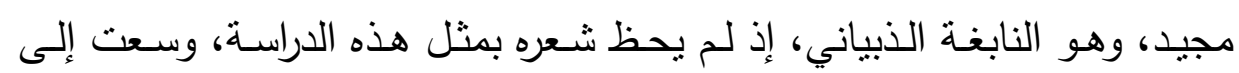

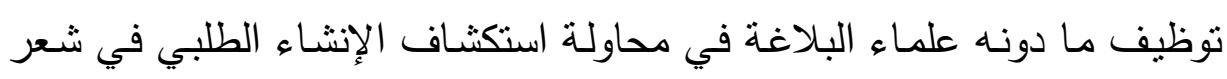
النابغة، ودراسته دراسة بلاغية . توطية 


\section{Abstract}

This study aims to study the Demand Composition: Imperative, Interrogation, Prohibition, Vocative, Optative in Al-Nabighah Al-Dhubiani's Divan. The study is a rhetorical one. So it studied each subject of the Demand Composition. And it limited the poetic verses in each subject. It applied the rhetorical meanings for them. The new in this study is that it is the first one that studied the Demand Sentence in the poetry of an excellent Jahiliy poet, Al-Nabighah Al-Dhubiani, as his divan wasn't studied a rhetorical statistical study before. 


\section{مقدمة}

قسم البلاغيون الجملـة إلى خبر و إنشـاء أو مـا يسمى بـا لجملـة الخبريـة

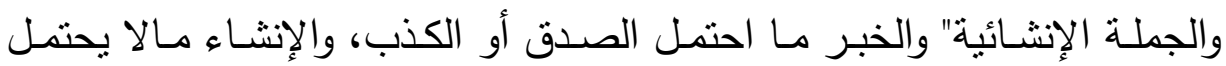

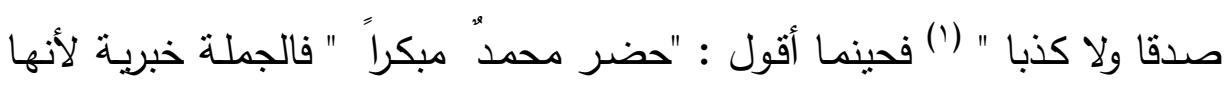

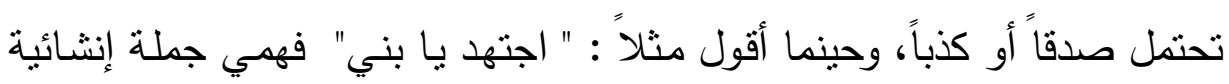

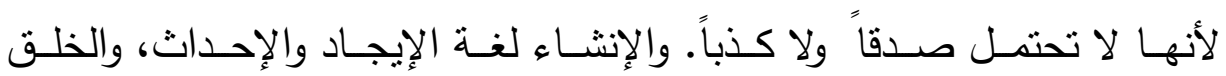

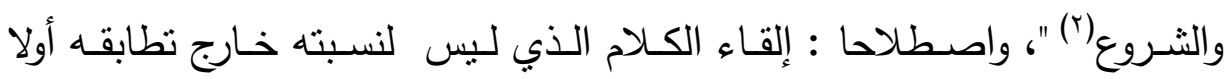
نطابقه" (r) (ن)

ويقسم الإنثاء إلى قسمين :طلبي وغير طلبي، فالطلبي ما يستدعي مطلوبا

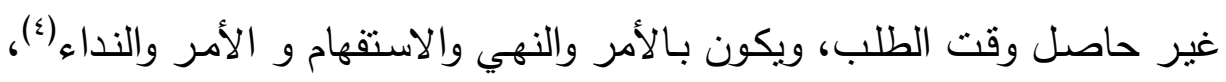

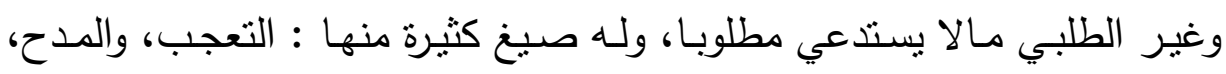
والذم، والقسم، والرجاء (0).

ويركز الباحثون على الإنشاء الطلبي لأن فيه لطائف عديدة، وهذا مالا يوجد في الإنشاء غير الطلبي. وتحاول هذه الدراسة نطبيق أقسام الإنشاء الطلبي في لإنساء فئه

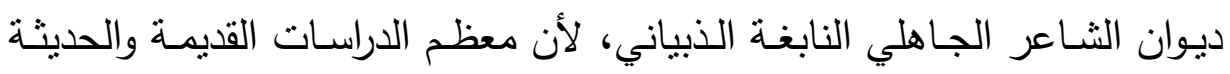

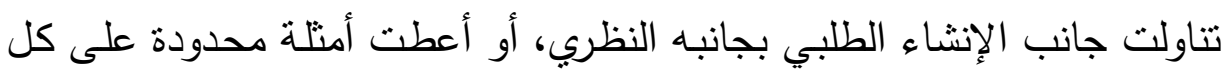
قسم من أقسام الإنشاء الطلبي، وبقيت هذه الدراسات التي بحثت هذاء الموضوع في شعر شاعرٍ ما بسيرة. ويمكن تلخيص أسباب هذه الدراسة بما بأني:

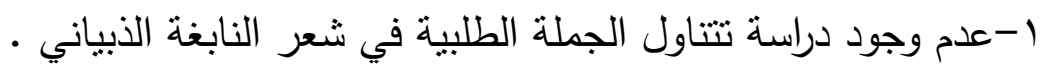
r- منزلة النابغة الذبياني الثعرية بين أقرانه الجاهليين.

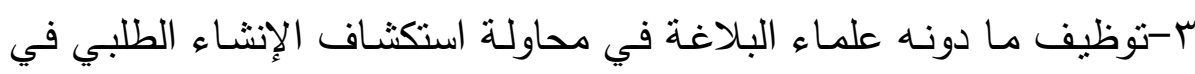
شعر النابغة ودراسته دراسة بلاغية. 
التعريف بالثاعر

النابغة الذبياني، هو زياد بن معاوية، ويكنى أبا أمامة، و يقال: أبا ثمامة (†) وقد

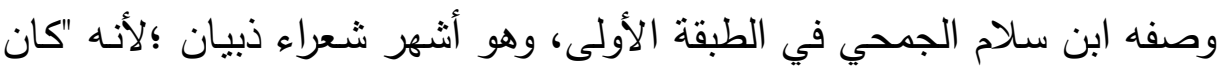

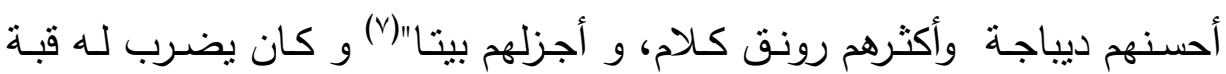

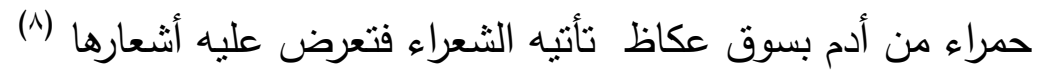

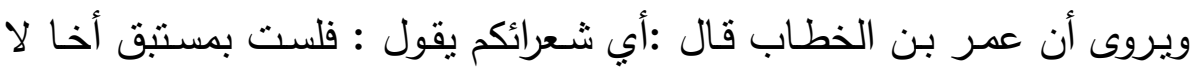

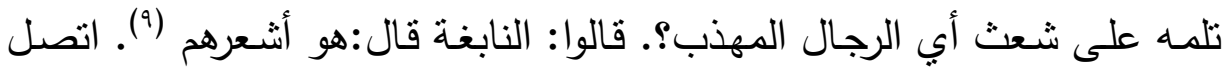

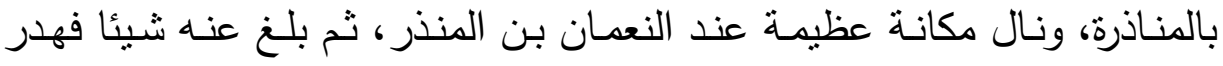

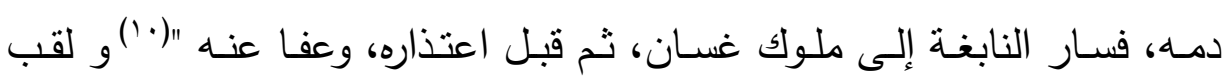

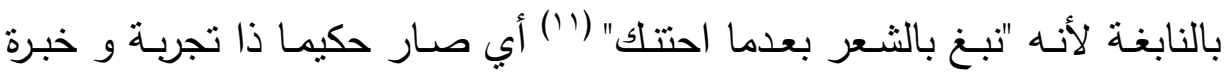
بالأمور

\section{أولاً: الأمــــــر}

وهو طلب الفعل على جهته الاستعلاء، أي حينما يكون الأمر حقيقياً يصدر الأبر

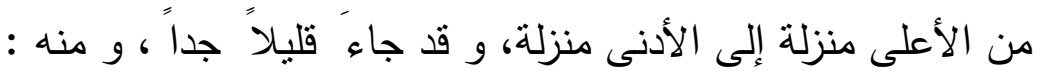

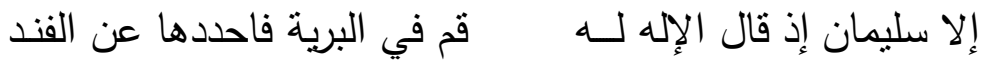

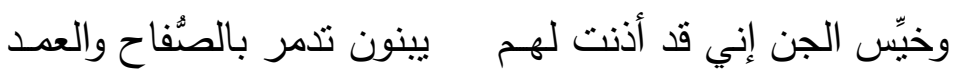

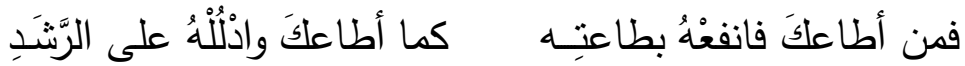

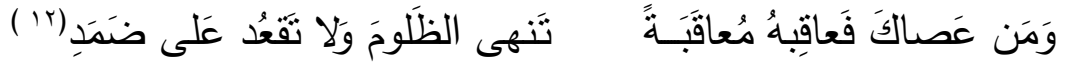
والصيغة التي جاء عليها الأمر هي فعل الأمر المباشر ، وعدّا الأمر حقيقياً

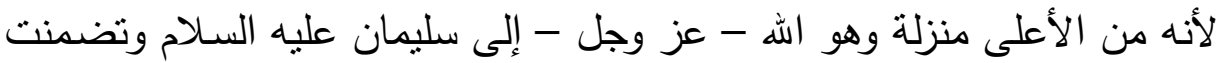

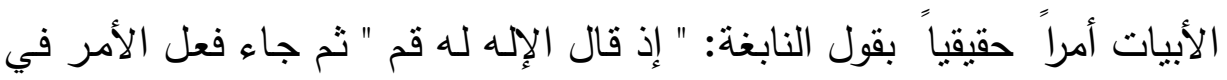

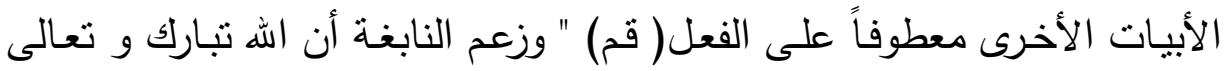

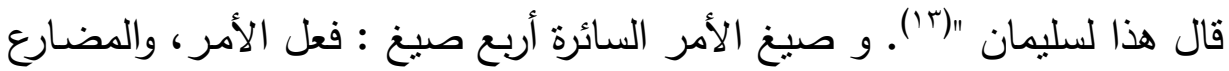


المقرون بلام الأمر، واسم فعل الأمر ، والمصدر النائب عن فعل الأمر •ووردت

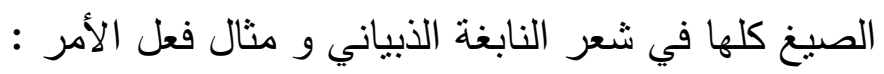

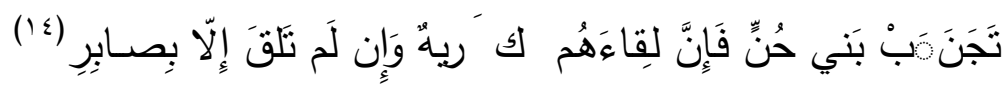

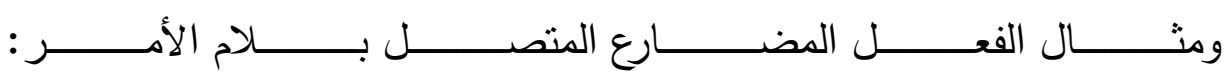
هنيئا لكم أن قد فنيتم بيوتنا مندّى عبيدان المحلّى باقرة)(10)

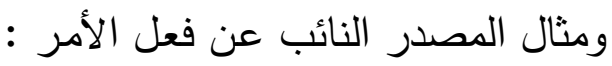

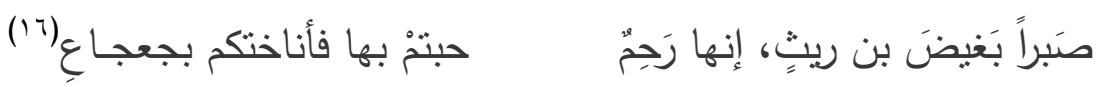

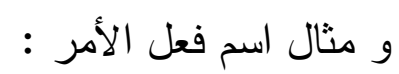
ألكني يا عيين إليك قولا سأهديه إليك، إليك عني (IV) واسم فعل الأمر هو

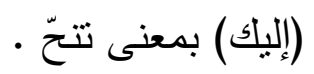
ويخرج الأمر إلى معان بلاغية كثثرة،و منها: 1-الدعاء كما في قوله:

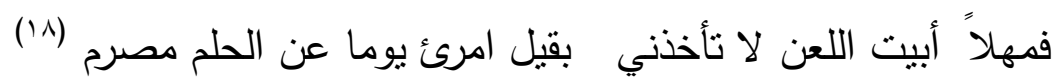

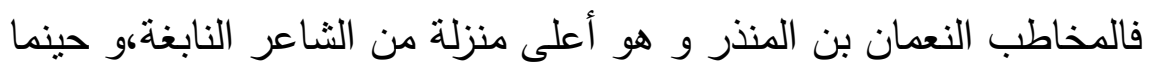

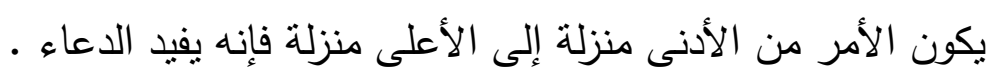

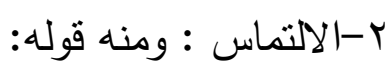

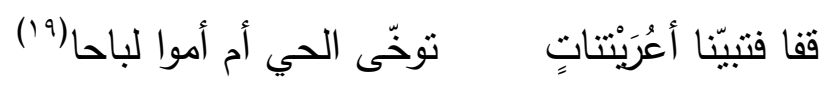
ب-النصح و الإرشاد:

واستيق ودك للصديق ولا تكن قتبا يعض بغارب ملحاحا (r.) و هو طلب يراد به النصيحة و الموعظة و الإرشاد . ع -التهديد:

جمع محاثك يا يزيد فإنني أعددت يربوعا لكم وتميما ('ال) فقد أفاد فعل الآمر التخويف والتحذير والتهديد . 
(rr)

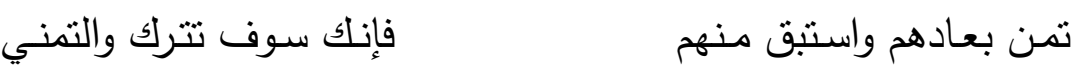

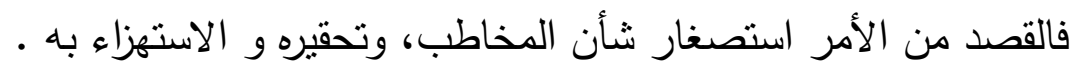

1-التخيير :

فصالحونا جميعاً إن بدا لكم ولا تقولوا لنا أمثالها عام (rT) فهو يخيرهم بالمصالحة أو عدمها، و يخرج الأمر إلى معان أخرى كالتسوية و

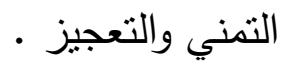
ثانياً: الاستفهام وهو طلب العلم بشيء لم يكن معلوما من قبل (צاج)، وأدواته إحدى عشرة

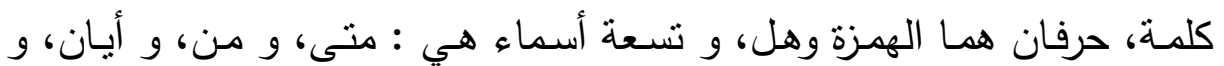

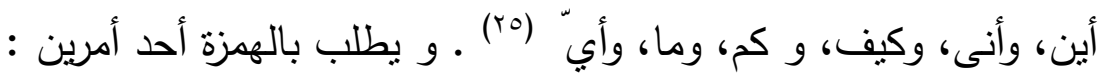

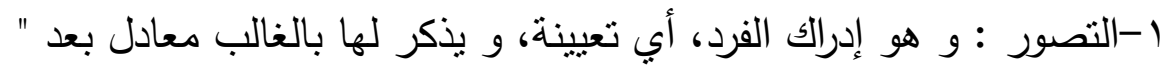

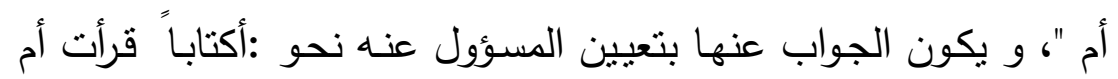
مجلة؟ (r) (r) r-التصديق ويكون الجواب عنها بـعم أو لا، و بطلب بها ثبوت شيء

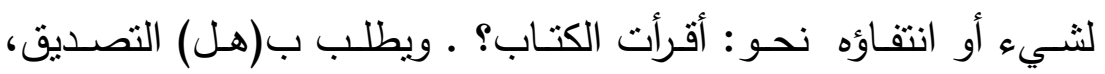

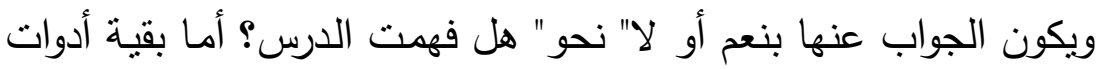

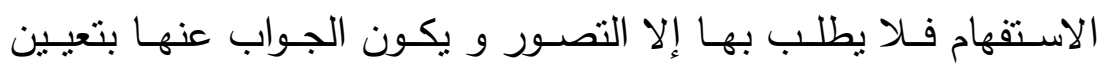

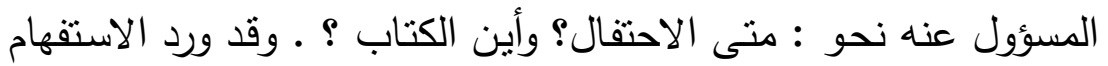

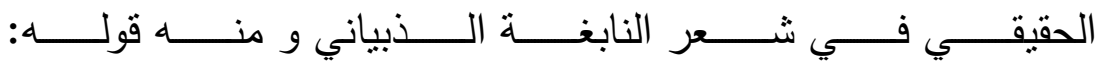

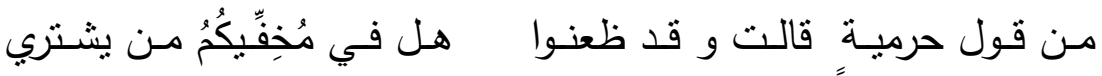

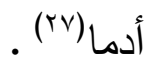


وقوله : فإني لا ألام على دخول ولكن ما وراءك يا عصام (r^)

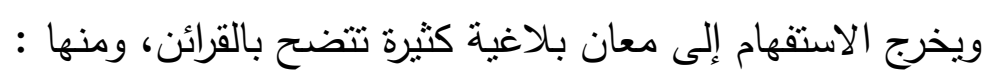

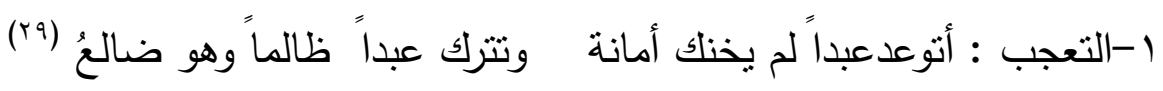

$$
\text { و من قوله : }
$$

على حين عاتبت الششيب على الصبا وقلت ألما أصح والثيب وازع

r-النفي : حلفت فلم أترك لنفسك ريبة وهل يأثنمن ذو إمة وهو طائعُ (r) :

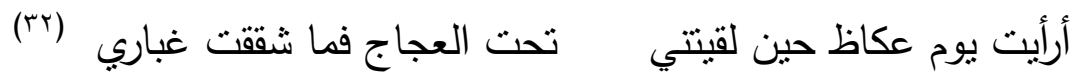

$$
\text { ع التعظيم : أي جبنت و لم تدخل في غباري • }
$$

يقولون حصن ثم تأبى نفوسهر وكيف بحصن والجبال جنوح (rr) فقد أفاد الاستفهام التعظيم لحصن بن حذيفة الذي يرثيه النابغة،ورو تضمن

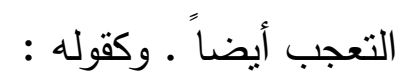

هلا سألت بني ذبيان ما حسبي إذا الدخان تغشى الأثمط البرما

0-التقرير : ألم أقسم عليك لتخبرني أمحمولٌ على النعش الهمام (ro) فقد خرج الاستقهام في الشطر الأول إلى معنى الثقرير •

$$
\text { 1-الإنكار : }
$$

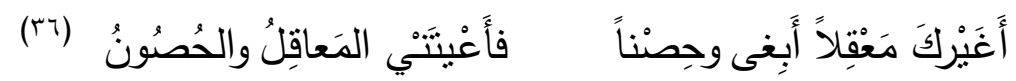

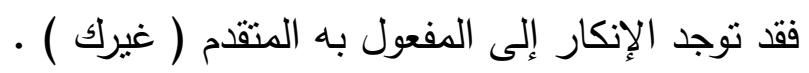

$$
\text { V الوعيد والتهديد : v }
$$

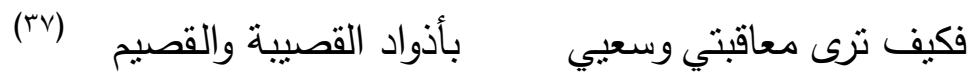


ثالثاً : النهي

وهو طلب الكف عن الفعل على وجه الاستعلاء، و له صيغة واحدة و هي

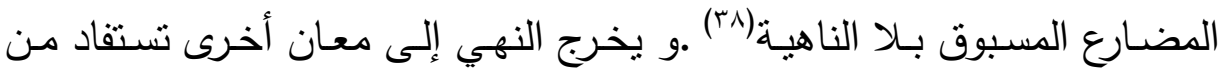

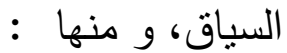

$$
\text { 1-الدعاء: كقوله : }
$$

فلا تتركني بالوعيد كأنني إلى الناس مطلي به القار أجرب(هa)

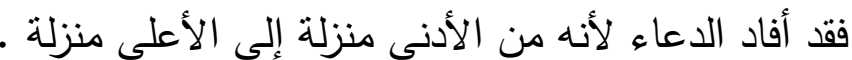

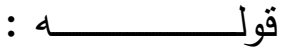

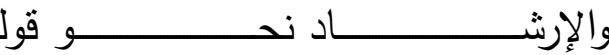

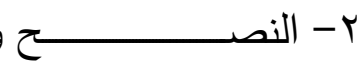

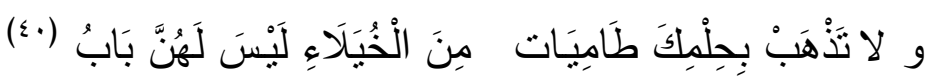

$:$ is

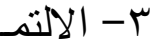

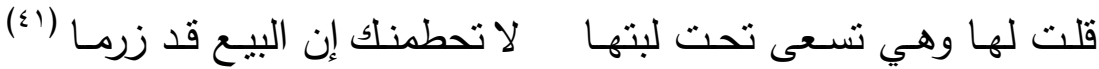

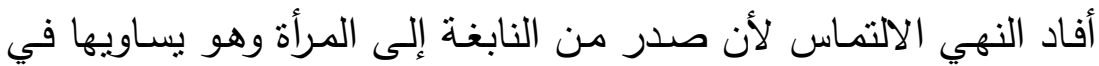

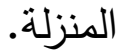

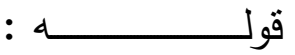

قون

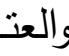
$\sqrt{-1}-\varepsilon$

لا ترهبيني بقوم وانظري نفري هل منل واحدهم من معشر رجل (r\&) رابعاً: النداء

وهو طلب إقبال المدعو على الداعي بأحد حروف مخصوصة ينوب كل حرف

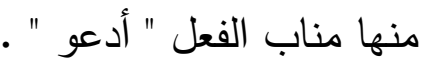

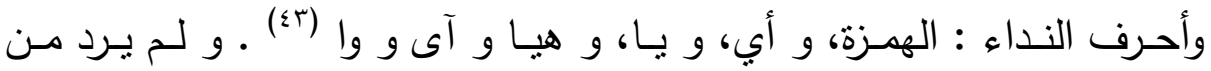

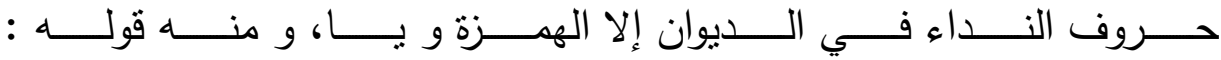

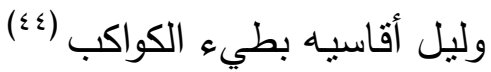
كليني لهم يا أميمـة ناصب

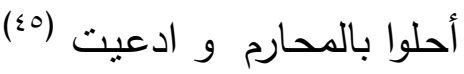

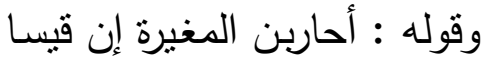

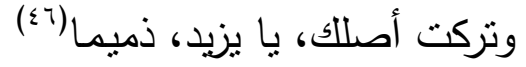
وقوله : ولحقت بالنسب الذي عيرتتي

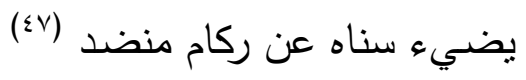
وقوله : أصاح ترى برقاً أريك وميضه لدي عيرلي 


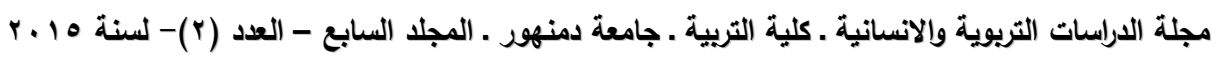

وقد يخرج النداء إلى معان بلاغية و منها :

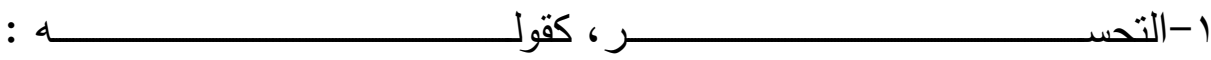

يا دار ميتة بالعلياء فالسند أقوت وطال عليها سالف الأبد(^؟)

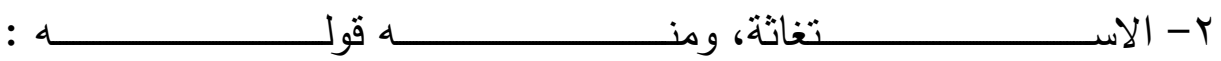

فيا للك حاجـة في صدر صب رأى الأظعان باكرة فباحا(9ء)

ب-التحقي،

ولحقت بالنسب الذي عيرتتي وتركت أصلك، يا يزيد، ذميما(0)

ع-التبيي

يا رب ذات خليل قد فجعن بـه وموتمين وكانوا غير أيتام (10)

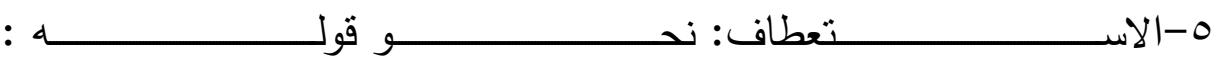

كليني لهم با أميمة ناصب وليل أقاسبه بطيء الكواكب (ro)

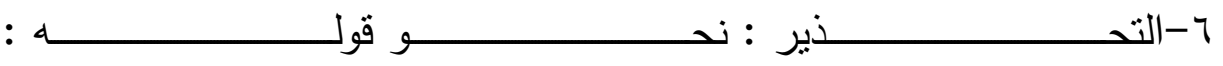

جزاً بجز وقتلا منل قتلكم مهلا حميض فلا يسعى بها الساعي (or)

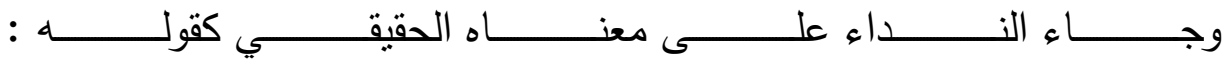

يا قوم إن ابن هند غير تارككم فلا تكونوا لأدنى وقعة جزرا(ع)

وتستخدم الهزة "و" "أي"للمنادى القربب و حروف النداء الأخرى للبعيد، وقد

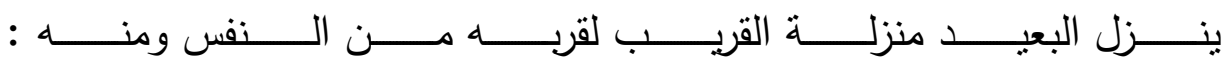
أحار بن المغيرة إن قيساً أحلوا بالمحارم و ادعيته(00)

وقد يخاطب القريب بـأداة نداء للبعيد ( بـا ) إظهار لغفلته و شرود ذهنه، ومنهـ

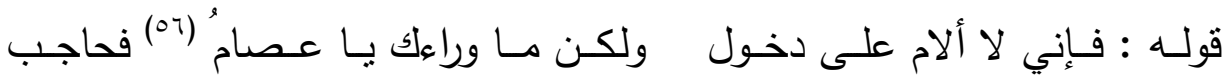
النعمان بن منذر و اسمه عصام قريب من النابغة مكانياً إلا أنه ناداه بأداة نداء

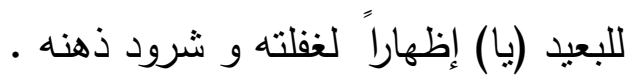




\section{خامساً : التمني}

وهو طلب حصول الثـيء المحبوب دون أن يكون للك طمع و ترقب في

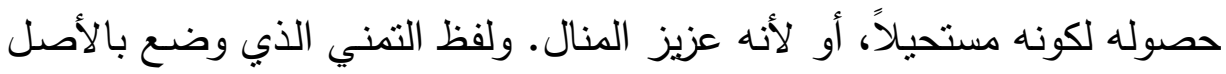

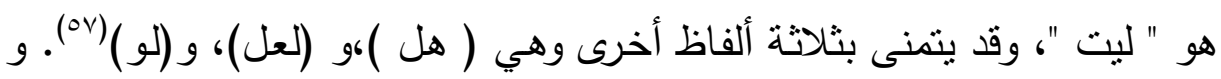

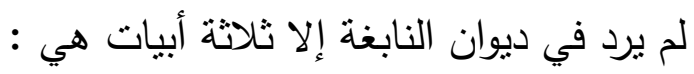

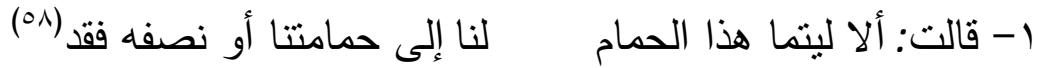

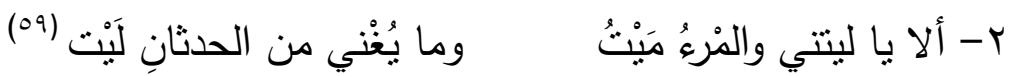

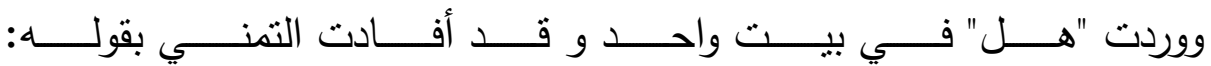

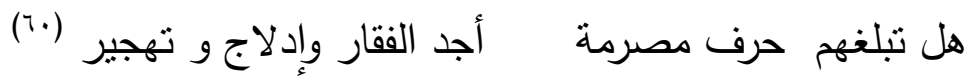
و سأرفق جدولاً يوضح كل قسم من أقسام الإنشاء الطلبي :

\begin{tabular}{|c|c|c|c|c|}
\hline بلام الأمــــارع المسـبوق & عن فعله النائسب & 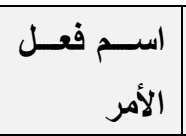 & فعل الأمر & الأمر \\
\hline ه أبيات & ؛ أبيات & بيت واحد & هب بيتاً & ه ؛ بيتاً \\
\hline عدد الأبيات & \multicolumn{2}{|r|}{ أداة الاستفهام } & \multicolumn{2}{|c|}{ الاستفهام(N بيتاً) } \\
\hline 11 ابيتا & \multicolumn{2}{|r|}{ الهمزة } & & \\
\hline ل أبيات & \multicolumn{2}{|r|}{ هل } & & \\
\hline ه أبيات & \multicolumn{2}{|r|}{ كيف } & & \\
\hline ع أبيات & \multicolumn{2}{|c|}{ ما } & & \\
\hline بيت واحد & \multicolumn{2}{|r|}{ أي } & & \\
\hline بيت واحد & \multicolumn{2}{|c|}{ | } & & \\
\hline r أبيات & \multicolumn{2}{|c|}{ من } & & \\
\hline \multicolumn{3}{|r|}{ الأداة } & \multicolumn{2}{|c|}{ النهي (9 19 بيتا ) } \\
\hline \multicolumn{3}{|c|}{ لا الناهية (9 19 بيتا ) } & \\
\hline عدد الأبيات & \multirow{2}{*}{\multicolumn{2}{|c|}{ أداة النداء }} & \multicolumn{2}{|c|}{ النداء(1) بيتا ) } \\
\hline$r$ & & & \multicolumn{2}{|c|}{+2} \\
\hline 14 & \multicolumn{2}{|c|}{ يا } & & \\
\hline$r$ & \multicolumn{2}{|c|}{ أداة النداء محذوفة } & & \\
\hline
\end{tabular}


مجلة الدراسات التربوية والانسانية ـ كلية التربية ـ جامعة دمنهور ـ المجلد السابع - العدد (ץ)- لسنة ه 1. ب

\section{خـاتـمــة}

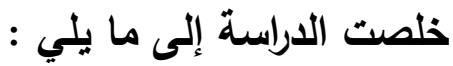

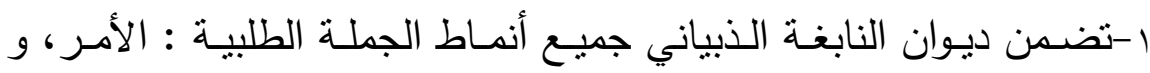

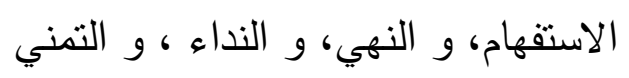

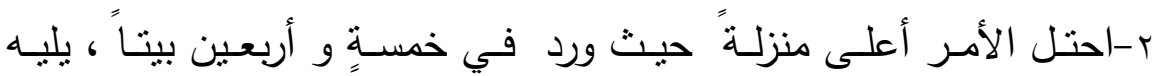

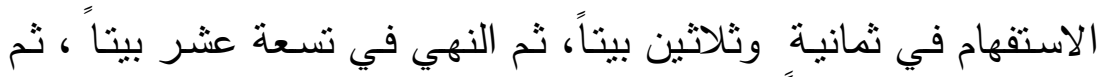

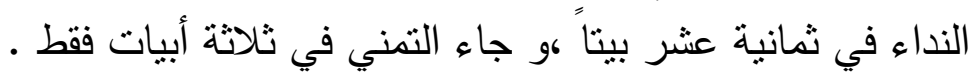

r-تنين أن الثاعر يعلي من مقامه باستخدام جملة الأمر بكثرة .

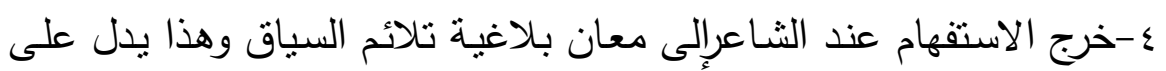
إبداعه في توظيف الجملة الاستفهامية.

ه-ترفـد الدراسـة الدروس البلاغيـة بشـواهد مـن شـعر النابغـة على الجملـة الإنشائية الطلبية ؛ لأن الثواهد البلاغية قلبلة ومتكررة في كتب البلاغة لبنة 


\section{النهوامش}

1-عباس،ضضـل حسـن، البلاغة فنونهـا وأفنانهـا،طا ،(دار الفرقـان، 910 ())،

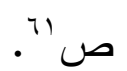

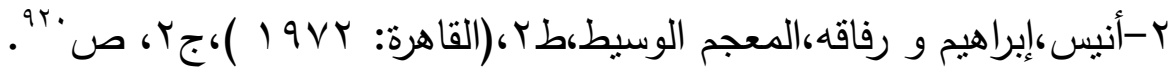

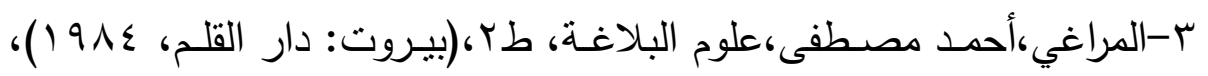

صن

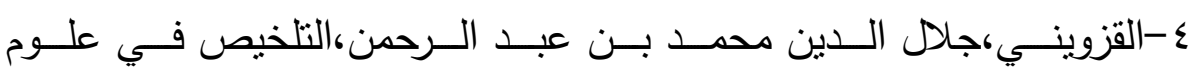

البلاغـةط ا، شرح:عبد الرحمن البرقوقي،(مصر :المكتبة التجاريـة الكبرى،

$$
.^{10 \gamma} \operatorname{lac}(19 . \varepsilon
$$

0-الجـــارم،علي و مصـــــفى أمين،البلاغــــة الواضــــــة، (مصــــر : دار

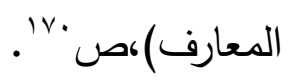

7-الجمحي،ابن سـلام، طبقات فحول الثـعراء، مطبعة المدني، تحقيق: محمود

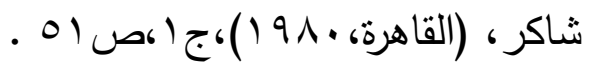

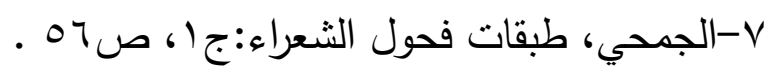

ᄉ-ابن قتيبة، عبداله بن مسلم، الثعر و الشعراء،طه،تقديم :حسن تميم،راجعه

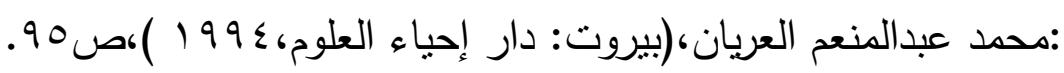

9-الجمحي،طبقات فحول الثعراء، ج (، صله

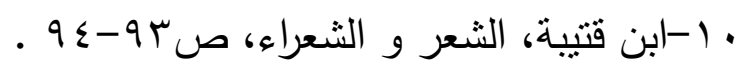

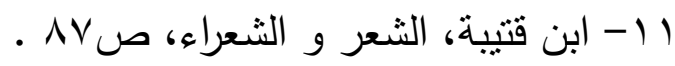

r ا -الذبياني،زياد بـن معاويـة،ديوان النابغـة الذبياني،تحقيق محمد أبو الفضـل

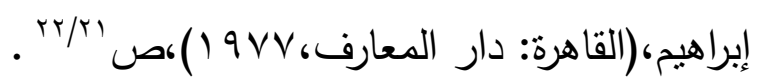

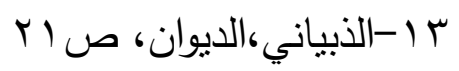

ع ا -الذبياني،الديوان، صـو

$$
\text { } 10
$$

TrV 


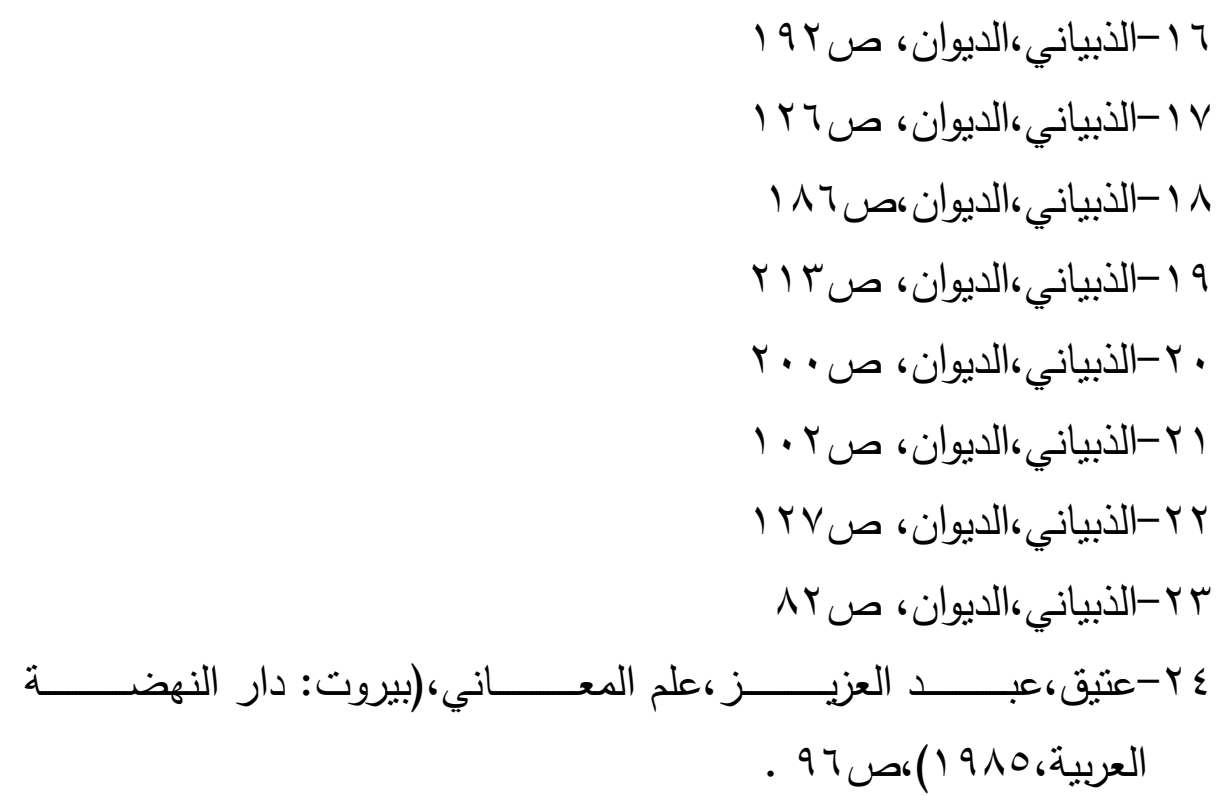

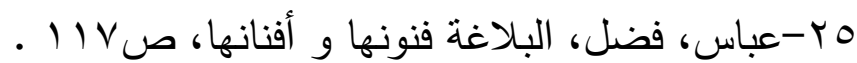

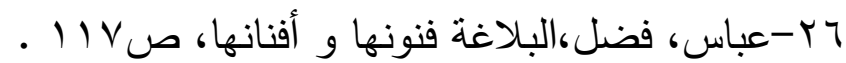

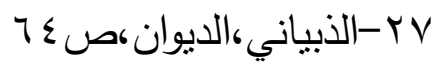

م r-الذبياني، الديوان،ص ه .

q ج-الذبياني،الديوان، صـم

• r-الذبياني،الديوان، ص بr.

اس-الذبياني،الديوان، صن

rس-الذبياني،الديوان، ص عـ

سب-الذبياني،الديوان، ص • 9

ع ب-الذبياني،الديوان، صبي

هب-الذبياني،الديوان، صـ ـ

צr-الذبياني،الديوان، ص r r r

rV

^r-عباس، فضل، البلاغة فنونها و أفنانها، صو ـ 1 . 
مجلة الدراسات التربوية والانسانية ـ كلية التربية ـ جامعة دمنهور ـ المجلد السابع - العدد (ץ)- لسنة ه 1. ب

q و-الذبياني،الديوان، صس

. ع -الذبياني، الديوان، ص 9 .

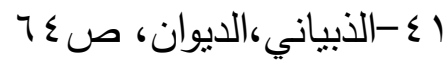

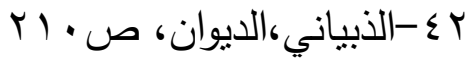

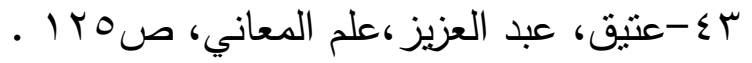

ع ـ -الذبياني،الديوان، ص • ع

o 0

ج - الذبياني، الديوان، ص r •

\&V

ـ ـ -الذبياني ،الديوان، ص ع

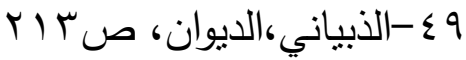

• ه-الذبياني،الديوان، ص r •

ا

ror-الذبياني،الديوان، ص • ع

ro-الذبياني،الديوان، ص 9 ا

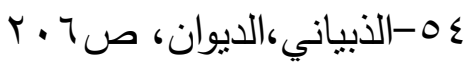

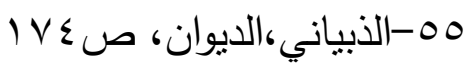

07

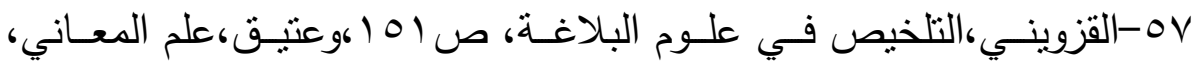

ص r Y (،وعباس، البلاغة فنونها و أفنانها، ص 11 ( 1 .

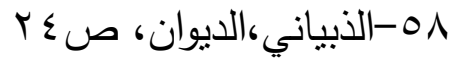

و

. 
قائمة المصادر والمراجع

ا-أنبس، ابراهيم ورفاقـه، المعجم الوسبط، طץ، إثـراف: حسن علي ومحمد

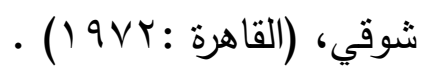

r-الجـارم، علـي ومصــفى أمسين، البلاغــة الواضــحة، طه، (مصــر : دار

$$
\text { (المعارف). }
$$

ץ-الجمحي،ابن سلام، طبقات فحول الثُعراء، مطبعة المدنى، تحقيق : محمود

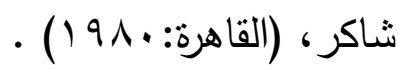

ع-الذبياني، زياد بن معاوية، ديوان النابغة الذبياني، تحقيق: محمد أبو الفضل

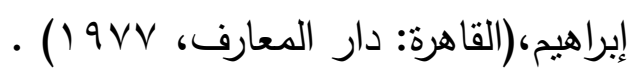

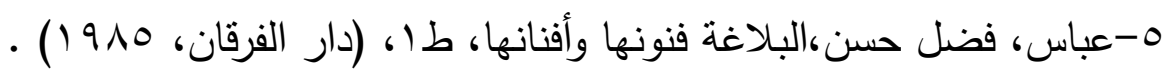

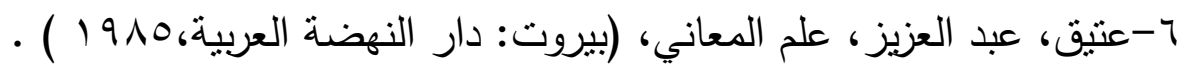

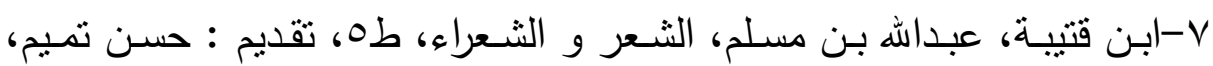

راجعه : عبد المنعم العربان، (بيروت: دار إحباء العلوم، ؟99 99 ) ) .

ᄉ-القزويني، جال الدين محمد بن عبد الرحمن، التلخيص في علوم البلاغة، طا، شرح : عبد الرحمن البرقوقي، (مصر : المكتبة التجارية الكبرى،

$$
\text { - (19. } \varepsilon
$$

9 9-المراغي، أحمد مصطفى،علوم البلاغة، طץ، (بيروت: دار القلم، عـ9 ( ). 